\title{
ДЕФОРМУВАННЯ ПЕРЕЗВОЛОЖЕНИХ ГРУНТІВ НАВАНТАЖЕННЯМ ВІБРАЦІЙНОГО ХАРАКТЕРУ
}

\author{
Калінін $\boldsymbol{C}$. I., кандидат технічних наук, дочент \\ Украӥна, Харків, Харківський національний \\ технічний університет сільського \\ господарства імені Петра Василенка
}

DOI: https://doi.org/ 10.31435/rsglobal_ws/30092018/6129

\section{ARTICLE INFO}

Received: 18 July 2018

Accepted: 22 September 2018

Published: 30 September 2018

\section{KEYWORDS}

vibration, wet ground, deformation, shear resistance.

\begin{abstract}
The paper considers the influence of the vibrational load on the deformation of soils with an increased moisture content. In the course of theoretical studies, it was established that the effect of vibration on soil deformation is observed when vibrational accelerations of a strictly defined limiting value are reached, which is usually called critical. It is established that the dependence of the critical acceleration on the specific static pressure is parabolic. In this case, the influence of vibration on the deformation of the soil is well described by the hyperbola equation. The presence of a limit of the sensitivity of the soil to vibrations is established, at the attainment of which a complete destruction of the cohesion forces is observed, which are not restored, and the internal friction reaches a maximum determined by the physical and mechanical characteristics of the soil. It is determined that the vibrations caused by the force in the vertical plane do not have a noticeable effect on the shear resistance. If the vector of the perturbing force coincides with the plane of shear, then the tangential stresses form an exponential dependence.
\end{abstract}

Citation: Калінін C. I. (2018) Deformuvannia Perezvolozhenykh Gruntiv Navantazhenniam Vibratsiinoho Kharakteru. World Science. 9(37). doi: 10.31435/rsglobal_ws/30092018/6129

Copyright: (C) 2018 Калінін С. I. This is an open-access article distributed under the terms of the Creative Commons Attribution License (CC BY). The use, distribution or reproduction in other forums is permitted, provided the original author(s) or licensor are credited and that the original publication in this journal is cited, in accordance with accepted academic practice. No use, distribution or reproduction is permitted which does not comply with these terms.

Вступ. Деформація грунтів під дією знакозмінних циклічних навантажень - вібрація, давно привертає увагу вчених. Здатність грунтів ущільнюватися під дією вібрації, зменшення опору вдавлення в грунт при певних режимах вібрації широко застосовуються, наприклад, в будівництві. Однак, з огляду на особливості роботи еластичного пневматика на агрофоні, можна говорити і про циклічне навантаження грунту останнім.

Для пояснення фізичної сутності впливу вібрації на поведінку грунтів під навантаженням висунутий цілий ряд гіпотез. Найбільш широкого поширення набуло представлення грунтів у вигляді коливальної системи, яка, в загальному випадку, має в'язкий опір коливань. При цьому опір коливань приймається пропорційним швидкості коливання.

У цьому випадку переміщення тіла, що здійснює плоскі горизонтально-обертальні коливання, описується системою диференціальних рівнянь виду: 


$$
\left\{\begin{array}{l}
m \frac{d^{2} z}{d t^{2}}+\alpha_{z} \frac{d z}{d t}+R_{z}(z)=P_{z}(t) \\
m \frac{d^{2} x}{d t^{2}}+\alpha_{x} \frac{d x}{d t}+R_{x}(x)=P_{x}(t) \\
J \frac{d^{2} \varphi}{d t^{2}}+\alpha_{\varphi} \frac{d \varphi}{d t}+\left[c_{\varphi} J_{F}+c_{x} F h_{0}^{2}-G h_{0}\right] \varphi-R_{x}(x) h_{0}=M(t)
\end{array}\right.
$$

де $G$ та $m$ - відповідно вага і маса тіла;

$\alpha_{z}, \alpha_{x}$ та $\alpha_{\varphi}-$ коефіцієнти опору коливань відповідно в вертикальній, горизонтальній площині і навколо вісі повороту при коливаннях $O Y$;

$R_{z}(z)$ та $R_{x}(x)$ - реакції грунту, що $€$ функціями переміщення;

$J$ та $J_{F}$ - відповідно момент інерції тіла і момент інерції площі опорної поверхні тіла відносно вісі, що проходить через центр ваги тіла перпендикулярно площині коливань;

$\varphi$ - кут повороту навколо вісі $O Y$, що проходить через центр ваги тіла перпендикулярно площині коливань;

$F$ - площа опорної поверхні тіла;

$h_{0}$ - відстань від опорної поверхні тіла до його центру ваги;

$c_{\varphi}$ та $c_{x}$ - узагальнені коефіцієнти опору відповідно повороту тіла навколо вісі $O Y$ і зсуву в напрямку вісі $X$;

$P_{z}(t)$ та $P_{x}(t)$ - проекції на відповідні координатні вісі зовнішньої сили, що діє на тіло; $M(t)$ - момент відносно вісі $O Y$, який діє на тіло.

Розв'язок системи рівнянь (1) дозволяє визначити положення тіла в будь-який момент часу. Проте, даний розв'язок існує далеко не у всіх випадках. Зокрема, при нелінійному характері функцій $R_{z}(z)$ та $R_{x}(x)$, які мають місце при деформації пластичного середовища, розв'язок рівнянь (1) в загальному вигляді не може бути отриманий. У цих випадках деформація грунтів під дією знакозмінних циклічних навантажень моделюється за допомогою різних реологічних моделей: в'язкої рідини; узагальненого пружно-в'язкого середовища; пружно-в'язко-пластичного середовища; моделей багатокомпонентного середовища зі скелетом, що деформується за законами пружності або пружно-пластичного тіла; резонансними явищами при виникненні пружних хвиль - хвиль напруги; використанням явища тиксотропії і ін.

Незважаючи на значну кількість проведених досліджень щодо впливу вібрації на деформацію грунту, до теперішнього часу ще не розкрита повністю фізична сутність цього явища. Більш того, як справедливо зазначає А. А. Дубровський, все ще обговорюється питання про те, що ж впливає на опір грунту деформаціям: швидкість вібрації або прискорення, і яка взагалі роль співвідношення частоти і амплітуди коливань.

Стосовно до цілей цього дослідження недостатня розробка загальної теорії деформації грунтів під дією вібрації ускладнюється ще й тим, що для грунтів підвищеної вологості подібні дослідження майже не проводились.

Окрім того, відомі роботи по вібрації грунту присвячені дослідженню режимів вібрації, що дозволяють зменшити опір вдавленню твердого тіла в грунт. Вібрація в цих умовах $\epsilon$ помічником людини, полегшуючи виконання технологічного процесу. В умовах же завдань, що стоять перед даною роботою, вібраційний характер навантажень 3 боку рушія машини на грунт $\epsilon$ шкідливим явищем, яке зменшує несучу здатність грунту i, як наслідок, погіршує прохідність машини. В такій постановці питання не виявлено в літературі досліджень щодо впливу вібрації на деформацію перезволожених грунтів.

Результати досліджень. Теоретичне вирішення проблеми впливу вібрації на деформацію перезволожених грунтів $є$ досить складним завданням. В даний час немає не тільки загального теоретичного вирішення проблеми, але і досить обгрунтованих 3 фізичної точки зору гіпотез, що створюють плацдарм для їі вирішення. В цих умовах найбільш плідним $\epsilon$ вивчення проблеми шляхом постановки експерименту. 
Дослідження впливу вібрації на деформацію грунту проводилося в грунтовому каналі. Для експериментів використовувалася вібраційна установка з зануренням штампа в грунт під дією власної ваги. Штамп мав прямокутну форму з розмірами $680 \times 150$ мм. Розміри штампа моделювали форму опорної поверхні колісного рушія трактора в масштабі 1:4.

Об’єктом дослідження був важкий суглинок вологості, яка відповідає 0,8 . .0,9 повного вологовмісту.

Як показує аналіз літератури, основним узагальненим параметром, що характеризує вплив вібрації на деформацію грунту, слід вважати величину прискорення $j g$ :

$$
j g=A \omega^{2} \sin \omega t
$$

де $A$ - амплітуда коливань;

$\omega$ - кутова швидкість

В якості критерію оцінки впливу вібрації на деформацію грунту використовувався коефіцієнт впливу вібрації:

$$
\eta_{6}=\frac{h_{b}}{h_{c m}}
$$

де $h_{6}$ та $h_{c m}$ - відповідно глибина занурення штампа в грунт при вібраційному характері навантаження і при статичному навантаженні. Величина $h_{c m}$ визначалася при дії на штамп навантаження $P$ :

$$
P=P_{0}+m A \omega^{2},
$$

де $P_{0}$ - статичне навантаження при вібраційному навантаженні;

$m$ - маса ексцентрику.

В результаті проведених досліджень встановлено:

1. Вплив вібрації на деформацію грунту $\left(\eta_{s}>1\right)$ починає проявлятися тільки при прискореннях, величина яких вище певного значення. Це значення прийнято називати критичним. Експерименти підтвердили існуючі в літературі дані про те, що величина критичного прискорення залежить від питомого статичного тиску на штамп. Разом 3 тим проведені дослідження показали, що на відміну від піску, для якого залежність $j_{s}=f(q)$, за літературними даними, є лінійною, у важких водонасичених суглинків зміна критичного прискорення в функції питомого статичного тиску відбувається нелінійно. В загальному вигляді ця залежність має параболічний характер:

$$
j_{\text {k.kp. }}=a_{\kappa p}+b_{\kappa p} q^{n_{k p}} .
$$

Числові значення параметрів рівняння (3) наведені на рис. 1.

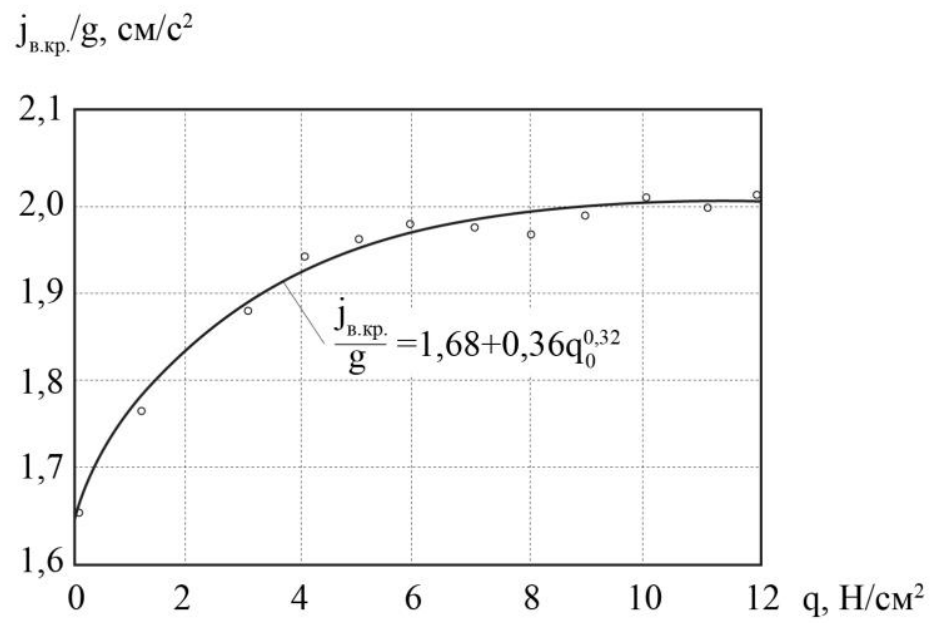

Рис. 1. Залежність прискорення коливань $j_{6}$ від значень статичного питомого тиску $q$ 
2. Інтенсивність вібрації, яка характеризується прискоренням $j_{6}$, істотно впливає на величину деформації грунту. В загальному випадку коефіцієнт впливу вібрації $\eta_{\varepsilon} \epsilon$ функцією двох змінних: прискорення коливання $j_{\varepsilon}$ i статичного питомої тиску $q$. Результати експериментальних досліджень по визначенню цієї залежності показані на рис. 2.

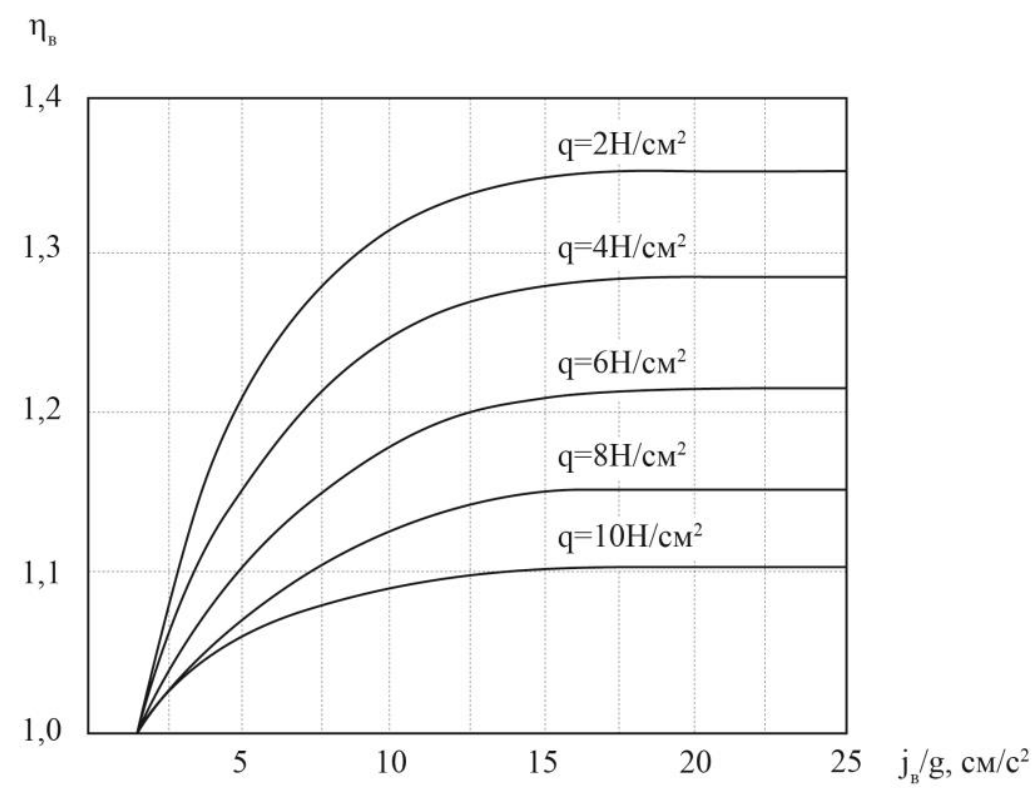

Рис. 2. Залежність коефіцієнту впливу вібрачії $\eta_{6}$ від прискорення коливань $j_{8}$ при різних значеннях статичного питомого тиску q

Вплив вібрації на деформацію грунту добре апроксимується рівнянням гіперболи:

$$
\eta_{B}=a_{0}(q)-\frac{1}{j_{6}-b_{0}(q)}
$$

Або, з урахуванням рівняння (3):

$$
\eta_{6}=a_{0}(q)-\frac{1}{j_{6}-\left[a_{k p}+b_{k p} q^{n_{k p}}-\frac{1}{a_{0}(q)-1}\right]} .
$$

Для важких суглинних грунтів високої вологості в діапазоні питомих статичних навантажень $0<q<100$ кПа рівняння (4) має вигляд:

$$
\eta_{8}=\frac{4,77}{q+3,19}-\frac{1}{j_{6}-1,66-0,36 q^{0,32}+\frac{3,19+q}{1,58-q}},
$$

де $j_{6}$ виражено в частках прискорення вільного падіння $g$.

Аналіз експериментальних даних (див. рис. 2) показує, що вплив вібрації на деформацію грунтів проявляється в певному діапазоні зміни $j_{\beta}$. Як зазначалося раніше, вплив вібрації починається за умови $j_{\varepsilon} \geq j_{\text {в.кр. }}$. Потім $\eta_{\beta}=f\left(j_{\beta}\right)$ інтенсивно зростає, асимптотично наближаючись до значення $\eta_{s \text { max }}$. При подальшому збільшенні $j_{6}$ вібрація не впливає на деформацію грунту. Значення $j_{6}$, при якому $\eta_{\varepsilon} \rightarrow \eta_{s \text { max }}$, можна назвати межею чутливості грунту до вібрації $j_{\text {s.lim }}$ (стосовно до випадку опору грунту зануренню в нього тіла під дією постійного статичного навантаження). Величина $j_{6 . \lim }$ залежить від $q$, збільшуючись з ростом останнього. 
Такий характер протікання залежності $\eta_{s}=f\left(j_{s}\right)$ може відображати фізичну сутність явища впливу вібрації на опір грунту деформації, якщо прийняти за основу існуючу в літературі гіпотезу про те, що під впливом вібрації відбувається зміна сил зчеплення і внутрішнього тертя грунтів.

В цьому випадку при збільшенні інтенсивності вібрації відбувається зменшення сил зчеплення, в першу чергу за рахунок руйнування сил капілярного натягу, і перехід від внутрішнього тертя спокою до динамічного тертя руху. Зміна ж величин зчеплення i внутрішнього тертя створює нову умову граничної рівноваги середовища, в результаті якої змінюється глибина довантажування деформатора в грунт.

При $j_{\varepsilon}=j_{6 . \lim }$ відбувається, скоріш за все, повне руйнування невідновлювальних сил зчеплення, а внутрішне тертя досягає мінімуму, обумовленого фізико-механічними характеристиками грунту, тому подальше збільшення інтенсивності вібрації не впливає на умову граничної рівноваги середовища.

Висновки. Коливання при збурюючій силі, вектор якої розташований у вертикальній площині, не роблять помітного впливу на опір зсуву $\tau$. При коливаннях, вектор вимушених коливань яких збігається 3 площиною зсуву, вплив вібрації на деформацію зсуву задовільно описується рівнянням, запропонованим В.А. Єршовим і Се-Дін-I:

$$
\tau_{j}=\tau e^{-m_{j}\left(j-j_{\tau}\right)},
$$

де $\tau$ - опір зсуву при безвібраційному характері прикладання зсувного зусилля;

$j_{\tau}$ - критичне прискорення, до якого не відбувається зміни опору зсуву;

величина $j_{\tau}$ як $\mathrm{i} j_{\text {s.кp. }}$, $є$ функцією питомого статичного тиску, яка в першому наближенні може бути представлена лінійною залежністю виду:

$$
j_{\tau}=a_{\tau}+b_{\tau} q,
$$

$m_{j}$ - коефіцієнт пропорційності, що залежить від характеристики механічного складу грунту.

\section{ЛIТЕРАТУРА}

1. Хаин В. Я. Теоретический анализ длительных осадок фундаментов при действии статической и динамической нагрузок / В. Я. Хаин // Динамика оснований и сооружений / под. ред. Д. Д. Баркан [и др.]. - Ташкент. - 1977. - С. $151-153$.

2. Филлипов О. Р. Экспериментальные исследования осадки штампов на водонасыщенном песчаном грунте при вибрациях / О. Р. Филлипов // Динамика оснований и сооружений / под. ред. Д. Д. Баркан [и др.]. - Ташкент. - 1977. - С. 153 - 155.

3. Работнов Ю. Н. Элементы наследственной механики твердых тел / Ю. Н. Работнов // М: Наука. 1977. -752 c.

4. Сеськов В. Е. О затухании упругих волн в грунтах / В. Е. Сеськов, В. Н. Кравцов / Будівельні конструкції: збірник наукових праць. - Вип. 69. - Київ, НДІБК. - 2008. - С.339 - 346.

5. Баркан Д. Д. Динамика оснований и фундаментов / Д. Д. Баркан. - М.: Стройвоенмориздат. - 1948. - 411 c.

6. Кудрявцев И. А. Влияние вибрации на основания и сооружения / И. А. Кудрявцев. - Гомель: БелГУТ. - 1999. - 247 с.

7. Красников Н. Д. Динамические свойства грунтов и методы их определения / Н. Д.Красников. - Л: Стройиздат. $-1970 .-240$ с.

8. Ляхов Г. М. Волны в плотных средах и нагрузки на сооружения / Г. М. Ляхов, Н. И. Полякова. - М.: Недра. - 1967. -232 c.

9. Ляхов Г. М. Волны в грунтах и пористых многокомпонентных средах / Г. М. Ляхов. - М.: Наука. 1982. $-288 \mathrm{c}$.

10. Рыков Г. В. Измерение напряжений в грунтах при кратковременных нагрузках / Г. В. Рыков, А. М. Скобеев. - М.: Наука. - 1978. -168 с.

11. Калінін Є. І. Вплив нестаціонарності гакового навантаження на буксування рушіїв колісного трактора / Є. І. Калінін, М. Л. Шуляк, В. П. Мальцев // Системи обробки інформації. - 2016. - №5. - С. 27 - 30. 